\title{
Taxes and Labor Supply: Portugal, Europe, and the United States
}

\author{
André C. Silva* \\ Nova School of Business and Economics
}

April 2008

\begin{abstract}
I relate hours worked with taxes on consumption and labor for Portugal, France, Spain, United Kingdom and United States. From 1986 to 2001, hours per worker in Portugal decreased from 35.1 to 32.6. With the parameters for Portugal, the model predicts hours worked in 2001 with an error of only 12 minutes from the actual hours. Across countries, most predictions differ from the data by one hour or less. The model is not sensible to special assumptions on the parameters. I calculate the long run effects of taxes on consumption, hours, capital and welfare for Portugal. I extend the model to discuss implications for Social Security. I discuss the steady state and the transition from a pay-as-yougo to a fully funded system.
\end{abstract}

Keywords: labor supply, consumption tax, labor income tax, welfare, Social Security.

JEL classification: E6, H3.

\footnotetext{
*Nova School of Business and Economics, Universidade Nova de Lisboa. Campus de Campolide, Lisboa, Portugal, 1099-032. Email: acsilva@novasbe.pt. Tel: 351-21-380-1600. This is a revised and extended version of the paper with the same title prepared for the III Conference "Desenvolvimento Económico Português no Espaço Europeu", organized by the Banco de Portugal and that took place on February 2006. The original version was intended for an academic and non-academic audience. It may be found at the conference proceedings. I thank Antonio Pinto Barbosa, Pedro Pita Barros, Paulo Brito (the editor), Susana Peralta and two anonymous referees for useful comments that greatly improved the paper. Published in the Portuguese Economic Journal, 7(2): 101-124, 2008, doi 10.1007/s10258-008-0029-1. The original publication is available at www.springerlink.com.
} 


\section{INTRODUCTION}

I relate hours worked in Portugal, France, Spain, United Kingdom and United States with consumption and labor taxes. I estimate the tax rates during 1970 to 2001 and compare the model predictions on hours worked per worker with the actual values for each country. Taxes predict the general trend in hours worked for all countries. Most predictions differ from the actual values by one hour or less. I calculate welfare implications and extend the model to study the effects of a change from a pay-as-you-go Social Security system to a fully funded system.

I use the neoclassical model in Prescott (2004) and Cooley (1995). In order to use data the most comparable as possible, all data are from the OECD publications Revenue Statistics and National Accounts and the OECD labor market statistics.

To obtain a correspondence from the actual tax systems to the taxes in the model, I use the method of Lucas (1990) and Mendoza, Razin and Tesar (1994), also used by Prescott (2002 and 2004). The tax rates are calculated by the ratio between tax revenues and the tax base. The five countries have different consumption and labor tax rates and different paths during 1970 to 2001 . The consumption tax is in general smaller for the United States and higher in France. It grew faster in Portugal and Spain during the period. The labor tax is in general higher in France. In the other countries, the labor tax rates converged approximately to the same value, lower than in France, in 2001. An additional contribution of the paper is to calculate the effective tax rates, the tax rates obtained by this method, for the five countries.

For Portugal, the predictions for hours worked are above the actual values for 1986 and have a difference of less than one hour in 1993-1996 and 2000-2001. For Spain, the predictions are above one hour for only 1993-1996. The model is able to predict the value of hours in most cases with an error of one hour and to follow the general trend. Especially for the period 2000-2002, the model predicts more hours than the actual 
hours for France. The legislation on the reduction of the working week in France may have a greater role than taxes in this period. I fix preferences and institutions across countries and time: the calibration for these predictions uses data for the period 19701975 and does not use data for Portugal and Spain. As the model predicts the general pattern of hours worked, and the calibration fixes preferences and institutions, taxes have an important effect in the number of hours worked.

The results show that taxes influence behavior, especially, labor supply. The conclusions do not rely on specific assumptions. I study several changes in the parameters and in the method to calculate effective taxes. Even with the changes, the model predicts hours in most cases with an error from the actual hours of one hour or less.

\section{Policy Implications}

Why do these results matter? I investigate three policy implications: (1) the long run effects of taxes on hours, capital, output, and welfare; (2) the long run effects of a change from a pay-as-you-go (PAYG) Social Security system to a fully funded system; and (3) the transitional effects of the same change in the Social Security system, from a PAYG to a fully funded system.

Consider the long run effects of taxes. As taxes change the decision of hours, an increase in taxes decreases consumption, capital, output, and welfare. The welfare effects are substantial. A decrease in taxes from 45 percent, the level in Portugal, as calculated by the effective taxes, to 37 percent, the level in the United States, is equivalent to a welfare gain of 6.8 percent in terms of current consumption. This welfare compensation takes into account the level of government expenditures: I maintain the ratio of government consumption to output constant. As output increases, keeping the government to output ratio constant increases government consumption. Considering private consumption only yields a welfare compensation of 5.8 percent. I also calculate the effects of the increase in the consumption tax in Portugal in 2002 and 2005. The total increase implies a welfare cost of 1.5 percent. 
For the second and third implications, I extend the model to calculate the effects of a change from a pay-as-you-go Social Security system to a fully funded system. The effect on hours affects the financing of Social Security. A decrease in Social Security taxes increases hours worked and helps to finance a transition from a PAYG to a fully funded system.

For the long run, I compare the scenarios with the current PAYG system and with a fully funded system. The welfare gains are substantial, in the order of 9.5 percent in terms of consumption. Moreover, consumption, output and capital are higher in a fully funded system.

For the transition, agents have the option to stay in the current system or to move to a fully funded system. The difficulty of the transition is to finance the agents that decide to stay in the current PAYG system. I study two options of financing. In the first, the government issues bonds to pay for the gap between current contributions and benefits. In the second, the level of government consumption temporarily decreases to balance revenues and expenditures. The options are also different in the level of non Social Security transfers for generations born after the change and in the path of government consumption. Even considering the transition, the welfare gains are substantial, 4.8 percent or 3.0 percent according to the method of financing.

Hours worked in the market refer to hours used in the legal market for production. One effect of a decrease in hours worked is the decrease in market production and, therefore, less consumption and welfare. Even if total hours stay constant, when labor flows from market to nonmarket activities, there can be welfare losses as the economy could be more efficient in market activities. Moreover, the decrease in market work can correspond to an increase in the underground economy. As taxes increase, the incentives for nonmarket work increase and so the economy works less efficiently.

In sections 2, 3 and 4 below I discuss the model, calculate effective tax rates and compare the predictions of the model with the data. Section 5 analyzes the sensitivity 
of the results to parameters and assumptions. Section 6 discusses policy implications: welfare implications and the implications for Social Security. Section 7 concludes.

\section{TAXES AND THE DECISION OF CONSUMPTION AND LABOR}

The elements of the model are standard: a decision on consumption and labor, consumption and labor taxes, a government sector, and a production sector. It is the same model as used by Prescott (2004) and it is in the same spirit of the models in Cooley (1995).

A representative consumer, infinitely-lived, has preferences

$$
\sum_{t=0}^{\infty} \beta^{t}\left[\log c_{t}+\alpha \log \left(100-h_{t}\right)\right]
$$

where $c_{t}$ and $h_{t}$ denote consumption and hours of work in the market respectively. $\beta$ is the intertemporal discount parameter, $0<\beta<1$, and the number 100 is a normalization of the number of hours per period ${ }^{1}$. The parameter $\alpha$ is a positive constant and it will be used to calibrate the model to the actual economies.

The consumer faces the budget constraint

$$
\left(1+\tau_{c}\right) c_{t}+\left(1+\tau_{x}\right) x_{t}=\left(1-\tau_{h}\right) w_{t} h_{t}+r_{t} k_{t}-\tau_{k}\left(r_{t}-\delta\right) k_{t}+T_{t}
$$

in every period. $x_{t}$, and $k_{t}$ denote investment and capital respectively. Taxes on consumption, investment, capital and labor are represented by $\tau_{c}, \tau_{x}, \tau_{k}$ and $\tau_{h}$ respectively. $\delta$ and $T_{t}$ denote the depreciation of capital and government transfers. All prices are in terms of the consumption good. The model considers the decision of consumption, labor and savings of an employed worker. It does not consider the decision of entering or not in the labor force as a job searcher. The law of motion of

\footnotetext{
${ }^{1}$ It is approximately the number of productive hours available per week.
} 
capital is $k_{t+1}=(1-\delta) k_{t}+x_{t}$.

The tax systems in the world are much more complicated than what we have in the budget constraint above. There are tax brackets, exemptions, subsidies and so on. These complications do not change the basic point of the analysis. In section 3 , I map the tax revenues and the tax bases to the effective taxes in the model.

Firms combine capital and labor to produce goods. Capital and labor prices are given respectively by $r_{t}$ and $w_{t}$. Let $y_{t}$ denote production. The production function is $y_{t}=A_{t} k_{t}^{\theta} h_{t}^{1-\theta}$, where $A_{t}$ is the total factor productivity and $\theta$ is the capital share, $0<\theta<1$. $A_{t}$ will not affect the quantity of hours worked and will not be important for our purposes. Let $g_{t}$ denote the quantity of goods consumed by the government. The resource constraint is $c_{t}+x_{t}+g_{t}=y_{t}$.

The government collects taxes to pay for government consumption. Any difference between tax revenues and government consumption is given back to consumers in the form of transfers $T_{t}$. Therefore, the government budget constraint is $g_{t}+T_{t}=$ revenues from taxes. Equilibrium allocations are such that consumers and firms maximize welfare and profits, the government budget constraint holds and the resource constraint holds.

Solving the model

A full solution of the model involves the equilibrium values of $c_{t}, h_{t}, x_{t}$ and $k_{t}$. Here we are concerned with the behavior of hours worked and so we focus on $h_{t}$.

The first order conditions imply $\frac{\alpha}{100-h_{t}}=\frac{1}{c_{t}} \frac{1-\tau_{h}}{1+\tau_{c}} w_{t}$. Taxes on labor or consumption have similar effects: a unit more of work brings less goods if the labor tax is higher or if the consumption tax is higher.

Firms choose capital and labor so that $w_{t}=(1-\theta) y_{t} / h_{t}$. With this, we have

$$
h_{t}=100 \times \frac{1-\theta}{1-\theta+\alpha \frac{c_{t}}{y_{t}} \frac{1}{1-\tau}},
$$


where $1-\tau \equiv \frac{1-\tau_{h}}{1+\tau_{c}}$.

Equation (3) is the key to understand how taxes influence labor supply. If taxes on labor or on consumption increase, then $\tau$ increases and so the number of hours worked decreases ${ }^{2}$.

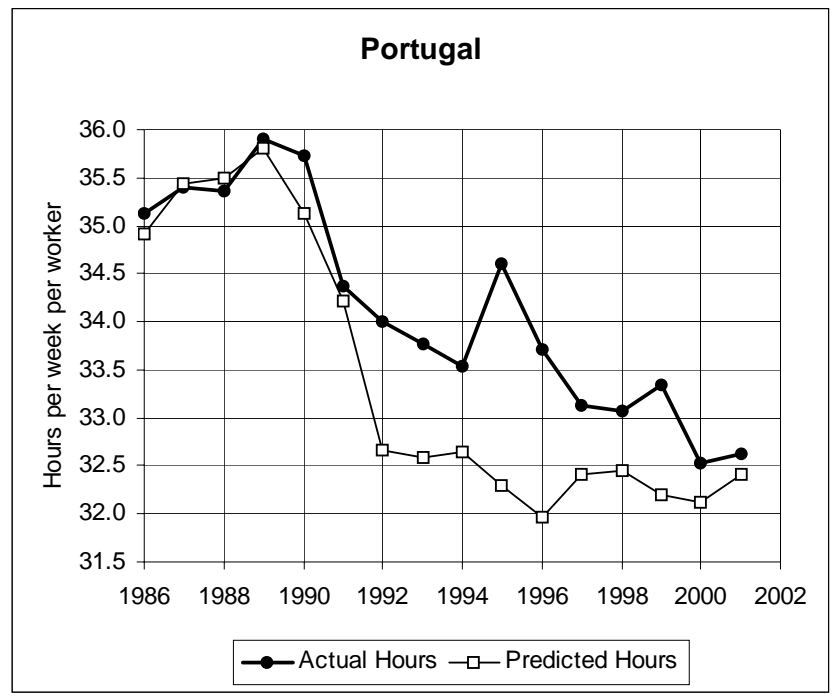

FIG. 1. Predicted hours obtained from the model developed in sections 2 and 3. Source of actual hours: OECD.

Figure (1) compares the predictions from equation (3) with taxes for Portugal and $\alpha$ calibrated with the data for Portugal ${ }^{3}$. Hours worked per worker in Portugal decreased from 35.1 hours per week to 32.6 hours per week from 1986 to 2001. Consumption and labor taxes increased during the same period. The model predicts 32.4 hours worked in 2001. According to these results, with only the change in taxes during these 15 years, we can predict the number of hours worked with an error of a little more than 10 minutes, or less than 1 percent from the true value. The same model

\footnotetext{
${ }^{2}$ The ratio of consumption to production, $c_{t} / y_{t}$, depends on the expectations about the future. Although the ratio $c_{t} / y_{t}$ is an equilibrium variable, we only need its value, given by the data, to obtain a prediction for the number of hours worked.

${ }^{3}$ In the calibration, $\alpha$ is obtained such that the sum of square differences between the actual values and the predictions for the period 1986-1988 is minimized.
} 
predicts a decrease in the number of hours to 31.9 hours per week if there is a further increase of one percentage point of the taxes on consumption and labor.

The model follows the general trend up or down of hours worked, but it misses, for example, a peak of hours worked in 1995. Nevertheless, the model is surprisingly precise to follow the general trend.

\section{TAXES ON LABOR INCOME AND CONSUMPTION}

We have to relate consumption and labor taxes in the actual economies with the taxes in the model. In reality, we have several consumption taxes for the various goods and services. Similarly, income tax systems are progressive over income, allow for exemptions and deductions, and we have Social Security taxes. The taxes obtained with the procedure in this paper are in table 1 and in figure (2). The calculations follow the same principle: dividing the revenues from the tax by the tax base. We have data for tax revenues detailed by the origin and for National Accounts aggregates from the OECD database ${ }^{4}$.

The idea of using National Accounts to calculate effective tax rates has its origins in Lucas (1990) and was extended by Mendoza, Razin and Tesar (1994). Prescott (2002, 2004) also used this method and I am following closer his calculations. There are some differences in my calculations to yield longer series and being the most comparable as possible. Calculating directly with Mendoza, Razin and Tesar's method yields slightly different values moving in parallel. The differences do not modify the conclusions ${ }^{5}$.

For the tax on consumption $\tau_{c}$, I divide revenues from indirect taxation, IT, by

\footnotetext{
${ }^{4}$ The sources of data are the OECD publications National Accounts, Detailed Tables: vol II and Revenue Statistics of OECD Member Countries. I used the OECD online dataset SourceOECD. The codes in the Revenue Statistics for each variable are as follows. Indirect taxation $I T$ is given by the sum of items 5110 and 5121. Social security contributions are given by item 2000, it considers contributions from employers and employees. Direct taxes of individuals, by item 1100 .

${ }^{5}$ See Pereira and Rodrigues (2001a, b) for a detailed discussion on the correspondence between statutory and effective tax rates in Portugal.
} 
household final consumption expenditure $C$ minus indirect taxation, as consumption expenditures include indirect taxation in the National Accounts, $\tau_{c}=\frac{I T}{C-I T}$.

\begin{tabular}{|c|c|c|c|c|c|c|c|c|c|c|}
\hline & \multicolumn{5}{|c|}{ Consumption Tax Rates } & \multicolumn{5}{|c|}{ Labor Tax Rates } \\
\hline & Portugal & France & Spain & $\begin{array}{c}\text { United } \\
\text { Kingdom }\end{array}$ & $\begin{array}{l}\text { United } \\
\text { States } \\
\end{array}$ & Portugal & France & Spain & $\begin{array}{c}\text { United } \\
\text { Kingdom }\end{array}$ & $\begin{array}{c}\text { United } \\
\text { States } \\
\end{array}$ \\
\hline 1970 & 7.2 & 27.0 & 6.9 & 18.3 & 7.0 & & 27.4 & 12.6 & 31.1 & 24.7 \\
\hline 1971 & 6.6 & 26.7 & 6.5 & 16.6 & 6.9 & & 27.3 & 13.6 & 30.7 & 22.6 \\
\hline 1972 & 6.4 & 27.0 & 6.4 & 15.3 & 6.7 & & 27.8 & 14.7 & 29.3 & 23.0 \\
\hline 1973 & 6.2 & 25.7 & 6.6 & 14.8 & 6.7 & & 27.1 & 15.3 & 28.8 & 23.2 \\
\hline 1974 & 6.3 & 25.7 & 6.1 & 14.4 & 6.6 & & 29.4 & 15.8 & 33.9 & 24.9 \\
\hline 1975 & 7.3 & 24.0 & 5.6 & 14.7 & 6.2 & & 31.2 & 18.4 & 37.8 & 24.3 \\
\hline 1976 & 9.0 & 25.3 & 5.3 & 15.0 & 6.1 & & 33.1 & 18.5 & 37.8 & 23.6 \\
\hline 1977 & 10.0 & 23.0 & 5.3 & 15.4 & 5.9 & & 34.1 & 21.5 & 34.6 & 25.1 \\
\hline 1978 & 10.4 & 24.0 & 5.7 & 14.7 & 5.9 & & 34.0 & 23.7 & 32.2 & 25.5 \\
\hline 1979 & 10.6 & 25.5 & 5.5 & 16.3 & 5.7 & & 35.8 & 24.6 & 30.3 & 26.9 \\
\hline 1980 & 13.8 & 25.1 & 6.0 & 18.3 & 5.8 & & 37.9 & 25.6 & 30.5 & 28.0 \\
\hline 1981 & 13.3 & 24.2 & 6.8 & 19.2 & 6.6 & & 38.3 & 26.8 & 32.0 & 29.1 \\
\hline 1982 & 13.4 & 24.7 & 7.1 & 19.4 & 6.3 & & 39.3 & 27.1 & 33.4 & 30.0 \\
\hline 1983 & 14.8 & 24.6 & 8.1 & 19.7 & 5.9 & & 40.7 & 29.1 & 32.4 & 27.5 \\
\hline 1984 & 13.7 & 24.8 & 10.0 & 20.6 & 6.0 & & 41.5 & 30.1 & 31.8 & 26.7 \\
\hline 1985 & 13.2 & 25.4 & 10.0 & 21.2 & 5.9 & & 41.3 & 28.3 & 31.1 & 27.7 \\
\hline 1986 & 21.8 & 25.0 & 12.6 & 20.4 & 5.7 & & 40.4 & 27.7 & 33.1 & 27.6 \\
\hline 1987 & 19.6 & 25.1 & 13.5 & 19.9 & 5.5 & & 41.0 & 31.1 & 31.0 & 28.7 \\
\hline 1988 & 19.4 & 25.4 & 13.8 & 19.8 & 5.6 & & 39.7 & 31.0 & 30.8 & 28.1 \\
\hline 1989 & 19.4 & 24.8 & 14.0 & 19.2 & 5.4 & 20.8 & 39.7 & 33.1 & 29.4 & 28.7 \\
\hline 1990 & 18.8 & 24.3 & 13.8 & 18.9 & 5.2 & 22.5 & 40.0 & 32.5 & 31.7 & 29.1 \\
\hline 1991 & 19.1 & 22.9 & 14.5 & 20.0 & 5.4 & 24.5 & 41.4 & 34.0 & 31.2 & 28.5 \\
\hline 1992 & 21.9 & 22.3 & 15.5 & 20.3 & 5.4 & 27.6 & 40.5 & 35.9 & 30.8 & 28.1 \\
\hline 1993 & 20.0 & 22.4 & 13.8 & 19.9 & 5.3 & 26.5 & 40.9 & 35.7 & 29.6 & 28.2 \\
\hline 1994 & 23.1 & 23.5 & 15.1 & 20.7 & 5.5 & 26.6 & 40.8 & 35.2 & 30.1 & 28.4 \\
\hline 1995 & 24.7 & 23.9 & 15.0 & 20.9 & 5.5 & 29.6 & 40.5 & 34.0 & 30.5 & 28.9 \\
\hline 1996 & 25.4 & 25.1 & 15.4 & 20.8 & 5.5 & 30.3 & 41.5 & 33.2 & 29.2 & 30.0 \\
\hline 1997 & 25.1 & 25.3 & 15.9 & 21.0 & 5.4 & 30.1 & 41.4 & 33.1 & 28.4 & 30.8 \\
\hline 1998 & 26.3 & 25.0 & 16.8 & 20.6 & 5.3 & 29.9 & 42.5 & 33.0 & 30.7 & 32.1 \\
\hline 1999 & 26.6 & 25.0 & 17.8 & 20.9 & 5.3 & 30.4 & 43.2 & 33.1 & 31.5 & 32.5 \\
\hline 2000 & 26.1 & 24.3 & 18.0 & 20.4 & 5.2 & 31.4 & 43.3 & 32.9 & 32.6 & 33.8 \\
\hline 2001 & 25.7 & 23.3 & 17.4 & 19.7 & 5.0 & 31.6 & 42.8 & 33.8 & 33.0 & 33.5 \\
\hline
\end{tabular}

Source: author's calculations as described in section 3.

As Mendoza, Razin and Tesar note, part of the indirect taxation comes from taxes paid by the government. This requires summing the tax base by the difference between government consumption and wages paid to government employees. As the denominator is bigger with the government sector, the tax on consumption calculated in this way is smaller. However, I compared the calculations with the two methods and the two series are very close, moving almost in parallel. For Portugal, the OECD 
database would allow us to calculate consumption taxes only for 1995-20016 ${ }^{6}$

The Social Security tax is obtained by dividing the Social Security contributions by the labor income. I use $(1-\theta)$ times GDP less indirect taxes as an estimate of the labor income, $\tau_{S S}=\frac{\text { Social Security Contributions }}{(1-\theta)(G D P-I T)}$. Indirect taxes are subtracted because GDP includes tax payments. I set $1-\theta=0.7$. This share is approximately constant over countries and time and the number used is conventional in models of this type ${ }^{7}$.

The average income tax is calculated by $\tau_{h}^{a v g}=\frac{\text { Direct Taxes of Individuals }}{G D P-I T-\text { Depreciation }}$. To obtain the marginal tax rate, I follow Prescott $(2002,2004)$ and multiply the average tax rate by the factor $1.6^{8}$. The labor income tax $\tau_{h}$ is then obtained as the sum of the Social Security tax and the marginal labor income tax, $\tau_{h}=\tau_{S S}+1.6 \tau_{h}^{a v g}$.

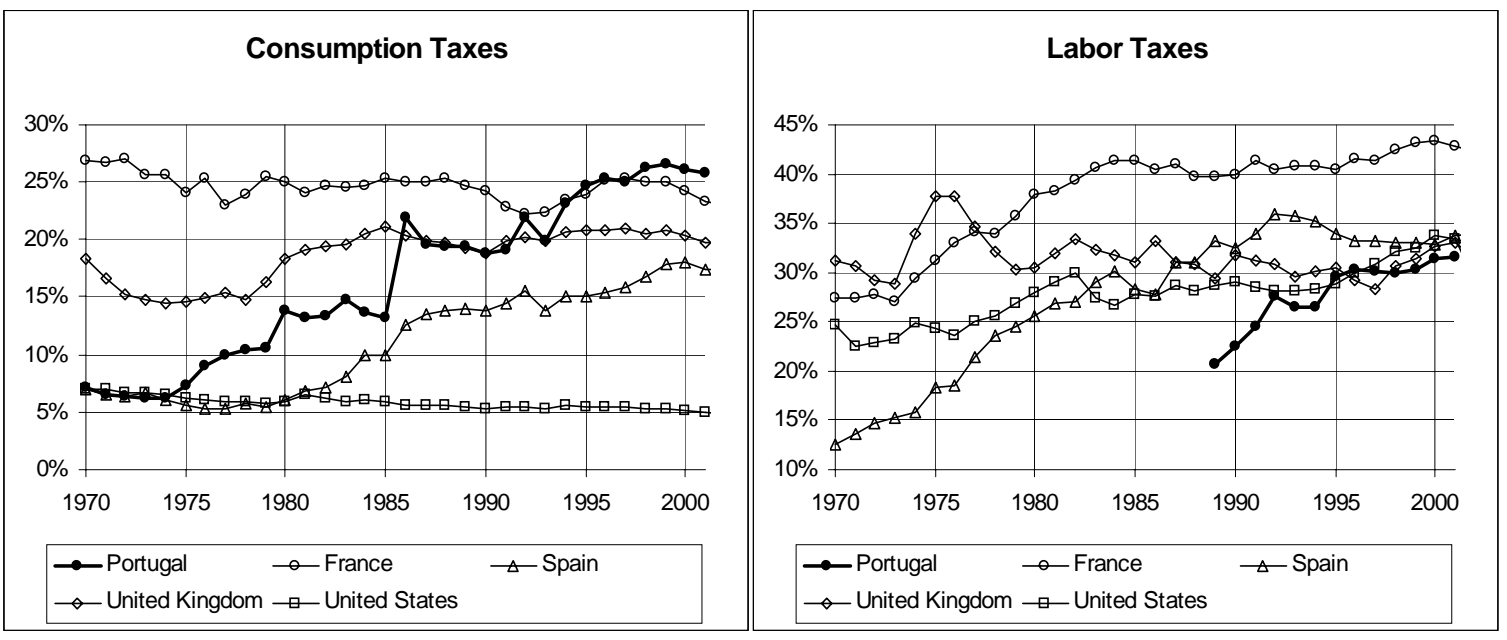

FIG. 2. Source: author's calculations based on OECD data.

\footnotetext{
${ }^{6}$ The difference between the calculations with or without the government sector are about five percentage points for this period.

${ }^{7}$ Gollin (2002) obtains further evidence for this number and for the stability of the labor share. The labor shares are approximately constant, in the range of 0.65 and 0.80 , once the labor income of the self-employed is treated carefully. The conclusions of the present analysis do not change if we consider other values in this range.

${ }^{8}$ This number is the increase in tax revenues if all workers had an increase in their incomes of one percent.
} 


\section{DATA AND PREDICTIONS}

We now turn to the predictions of the model. The key equation for the predictions is equation (3). Figure (3) shows hours per worker and the values of $\tau$ for Portugal and the United States from 1986 to 2001. Hours per worker decreased more in Portugal while taxes increased more in Portugal. This observation agrees with the model. To be more precise, we have to substitute the values of $\tau$ and $c_{t} / y_{t}$ in (3) and compare the predictions of the model and the actual values of hours per worker ${ }^{9}$.

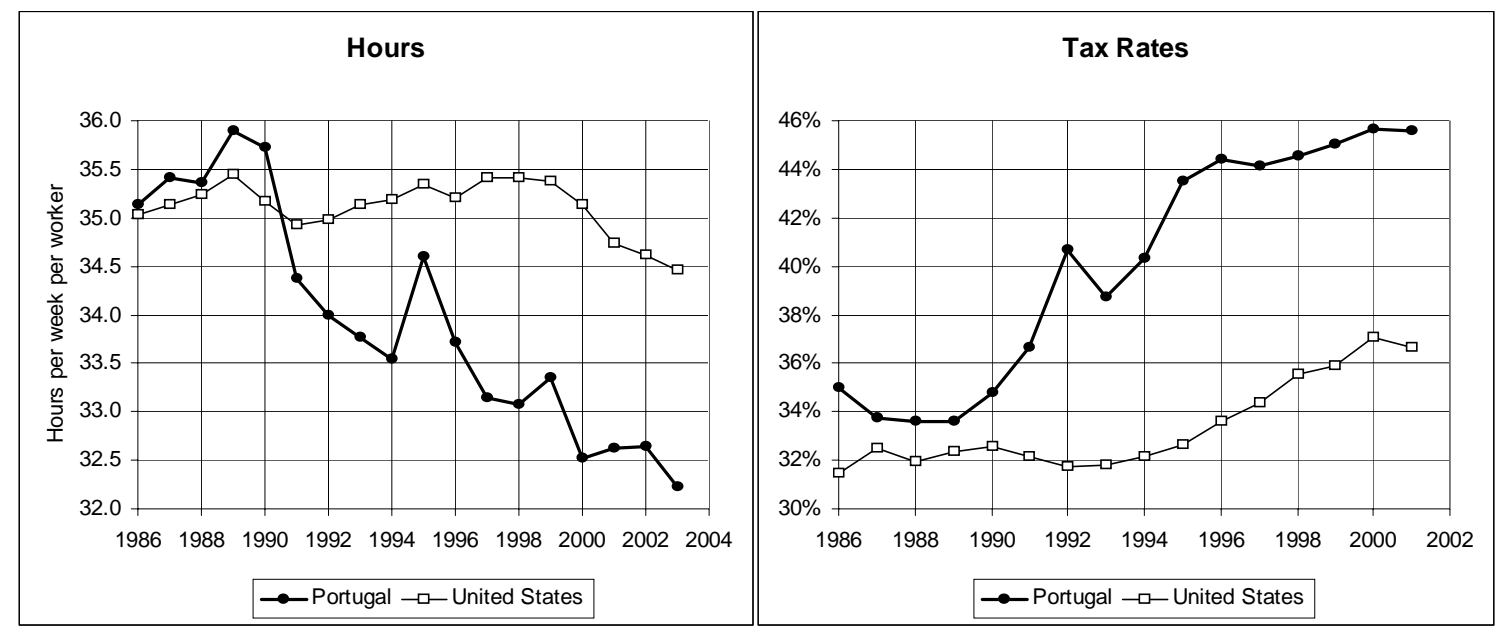

FIG. 3. Source for Hours: OECD. Tax rates: calculations by the author following section 3 .

In addition to Portugal the countries chosen for this study were France, Spain, United Kingdom and United States ${ }^{10}$. I first focus on four periods: 1970-1974, 19831986, 1993-1996 and 2000-2002. The first period is the first that we have data available for France, United Kingdom, and United States. The first observation available for

\footnotetext{
${ }^{9}$ In the model, labor supply from consumers and labor demand from firms act together to imply the equilibrium quantity of labor. Other models include additional features of the labor market that can also influence the behavior of hours worked. Here, I study how much the model in question is able to account for the pattern of hours worked.

${ }^{10}$ For the labor force, I use "average actual annual hours worked per person in employment" from the OECD. I divide the annual hours by 52 to write the values in weekly hours.
} 
Portugal is in $1986^{11}$, therefore I included the period 1983-1986. The period 2000-2002 is the last period that we have data available ${ }^{12}$.

I used two estimates for $c_{t}$ in equation (3). In the first case, I consider only private consumption net of indirect taxes. In the second, I also consider government consumption. So, $c_{t}=C_{t}$ - Indirect Taxes in the first case and $c_{t}=C_{t}+G_{t}$ - Indirect Taxes in the second case. $C_{t}$ and $G_{t}$ are the figures of private and government consumption in the National Accounts data. The value of $y_{t}$ is the same in the two cases: $y_{t}=G D P-$ Indirect Taxes. The justification for considering government consumption as part of $c_{t}$ is that it may substitute part of private consumption. However, I do not have a clear estimate of the degree of substitution between private and government consumption. Choosing a value could be thought as arbitrary. Therefore, I calculated the predictions for the two extreme cases, with zero and one-to-one substitution, and compared with the actual values ${ }^{13}$.

The parameter $\alpha$ sets the weights between consumption and leisure. It should have the same value for all countries to assess how much of the difference in hours is explained by the difference in taxes only. This parameter is obtained so that the difference between the actual and the predicted values of hours worked is minimized for the period 1970-1975 for France, United Kingdom and United States. It yields $\alpha=1.39$ and $\alpha=1.02$ when we consider respectively private consumption only and private and government consumption. The predictions of figure (1) were obtained for a value of $\alpha$ set to minimize the difference during the period 1986-1989 for Portugal, with only private consumption. This yields $\alpha=1.47$ and is used to assess how much of the change in hours during the period 1986-2001 may be accounted for changes in the tax rates for Portugal.

\footnotetext{
${ }^{11}$ Labor income taxes are available since 1989 for Portugal. I maintained the labor income tax rate during 1986-1988 equal to its value in 1989 to calculate $\tau$ from 1986 to 1988.

${ }^{12}$ Prescott (2004) focuses on the periods 1970-1974 and 1993-1996.

${ }^{13}$ Prescott (2004) adds $2 / 3$ of non-military government expenses to private consumption to obtain his measure of consumption.
} 
Table 2. Actual and Predicted Hours

\begin{tabular}{|c|c|c|c|c|c|c|c|c|c|}
\hline & \multicolumn{3}{|c|}{ Portugal } & \multicolumn{3}{|c|}{ France } & \multicolumn{3}{|c|}{ Spain } \\
\hline & Actual & Pred 1 & Pred 2 & Actual & Pred 1 & Pred 2 & Actual & Pred 1 & Pred 2 \\
\hline $1970-74$ & - & - & - & 35.9 & 37.2 & 36.4 & - & - & - \\
\hline $1983-86^{*}$ & 35.1 & 36.2 & 37.7 & 31.6 & 31.9 & 29.6 & 36.0 & 35.3 & 36.8 \\
\hline $1993-96$ & 33.9 & 33.6 & 33.5 & 30.2 & 32.6 & 29.9 & 34.9 & 33.9 & 34.0 \\
\hline \multirow[t]{3}{*}{$2000-02^{* *}$} & 32.6 & 33.5 & 32.4 & 28.3 & 32.4 & 29.8 & 34.9 & 34.6 & 34.7 \\
\hline & & \multicolumn{3}{|c|}{ United Kingdom } & \multicolumn{5}{|c|}{ United States } \\
\hline & & Actual & Pred 1 & Pred 2 & & Actual & Pred 1 & Pred 2 & \\
\hline $1970-74$ & & 36.6 & 34.8 & 34.8 & & 36.3 & 37.0 & 38.1 & \\
\hline 1983-86 & & 33.5 & 34.4 & 33.2 & & 35.1 & 35.2 & 36.5 & \\
\hline 1993-96 & & 33.3 & 33.7 & 33.4 & & 35.2 & 33.8 & 35.9 & \\
\hline 2000-02 & & 32.8 & 32.3 & 32.3 & & 34.8 & 32.1 & 34.5 & \\
\hline
\end{tabular}

Hours per week per worker. Pred 1: predictions with private consumption. Pred 2: predictions with private and government consumption. * 1986 only for Portugal. ** 2000-01 only for Portugal.

Source of actual hours: OECD.

Therefore we estimate the parameter $\alpha$ in two ways. In the first, we focus on Portugal and obtain the predictions in figure (1) as a starting point. In the second, we do not use the data for Portugal and use other countries and another period. In this second way the parameter $\alpha$ is set independently from the data for Portugal. Any difference in the predictions of hours worked across countries and through time is because of the difference in taxes and the difference in the ratio of consumption to GDP. I now focus on this second estimation of $\alpha$.

Table 2 compares actual and predicted hours. Each period shows the average of actual and predicted values. Each column fixes the value of $\alpha$. Therefore, I fix tastes on consumption and leisure and all kinds of institutional arrangements across countries. I allow only taxes to vary and the corresponding equilibrium value $c_{t} / y_{t}$.

Although the model abstracts from several potentially important features of the labor market, it is able to generate very reasonable estimates based only on the tax rates. Most numbers are around one hour of error from the actual value of hours 


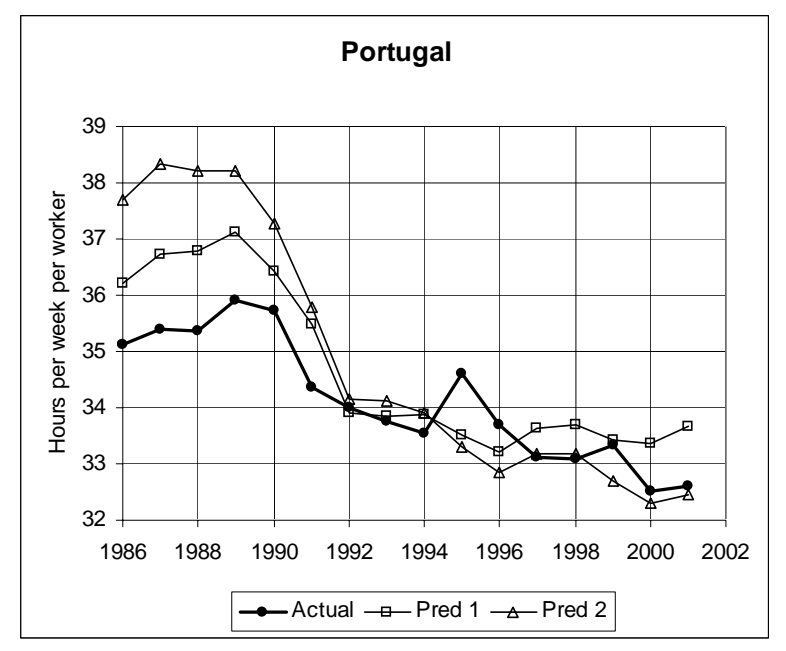

FIG. 4. Source of actual hours: OECD. Pred 1: predictions using only private consumption net of indirect taxes. Pred 2: predictions with private and government consumption net of indirect taxes.

worked. Only five predictions misses the actual numbers for more than two hours. According to table 2, the predictions for hours worked for Portugal are above the actual values for 1986 and are much closer for 1993-1996 and 2000-2001. For Spain, in only one period the model predicts hours with more than one hour of error. For the United Kingdom it misses the period 1970-1974 but it is good in predicting the other periods. For France, the model predicts more hours of work than the actual values specially for the period 2000-2002. It can be an effect of the new legislation on the reduction of the working week in France, and it can have a greater role than the change in taxes for this period.

Therefore, the model is good in predicting the general pattern of hours worked. As everything is fixed across countries and only taxes are allowed to vary, this shows that taxes have an important effect in the number of hours worked. The good fit is more surprising for Portugal and Spain as I have not used these countries to estimate the value of $\alpha$, and we could believe a priori that they are much different from the 

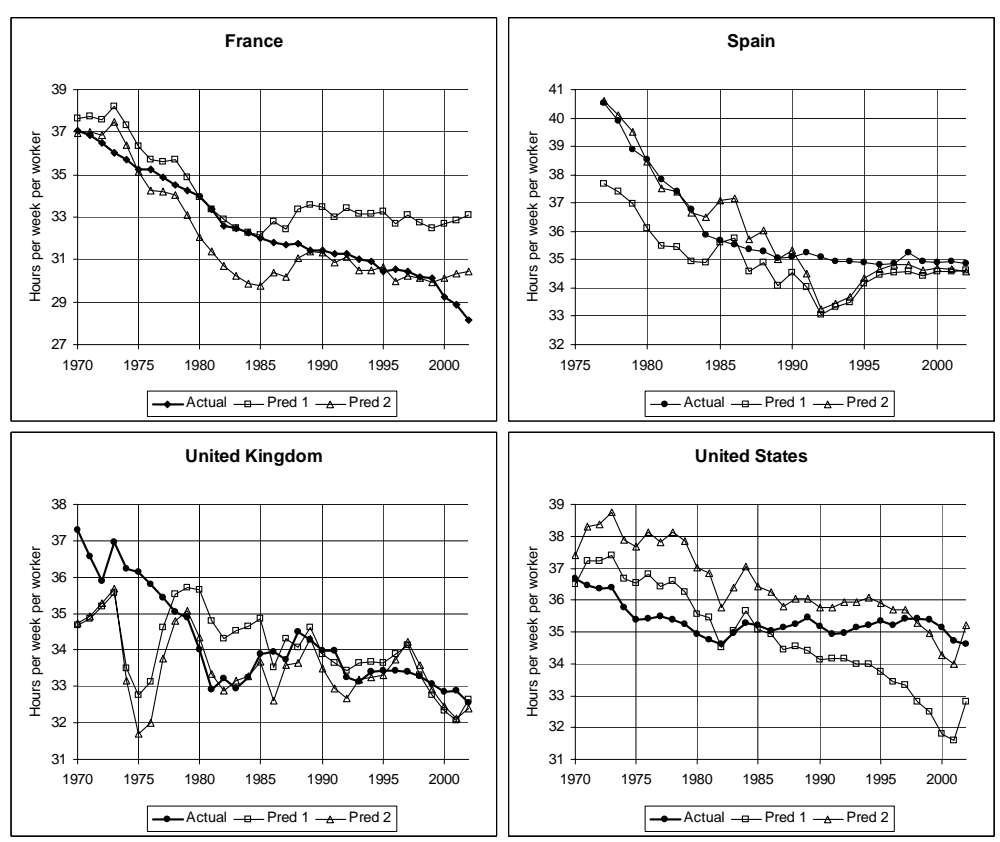

FIG. 5. See figure (4) for sources and definitions.

other countries apart from the difference in taxes. Figures (4)-(5) compare actual and predicted hours year by year.

I am using hours per worker in the analysis. Other models use hours per capita or hours per (working age) person. In the model, workers decide hours of work given that the decision of entering the labor market has already been made. Hours per person in Portugal were on average 2.4 hours lower than in the United States during 1986 to 2001. During the same period, however, hours per person were more or less constant as the number of people in the labor force increased. Prescott (2004) uses hours per person and he also finds an important effect of taxes on the supply of labor ${ }^{14}$.

\footnotetext{
${ }^{14}$ Davis and Henrekson (2005) provide empirical evidence on the effects of taxes on the labor supply and on the underground economy.
} 


\section{SENSITIVITY ANALYSIS}

I show in this section that the conclusions of the paper do not rely on specific assumptions. We still obtain that the labor supply can be explained by the evolution of the tax rates with reasonable changes in parameters and in the calculation of effective tax rates.

The analysis above opens the possibility of not having a good fit in several ways. First, all parameters were obtained independently from other sources and papers. Second, the procedure to calculate the effective tax rates was developed independently for a general application. Third, the parameter $\alpha$, which denotes the weight between consumption and leisure, was obtained with observations from other countries than Portugal and for a different time period. Those assumptions put much stress in the model as they make more difficult to fit the data. Moreover, there are two predictions for each country, one with private consumption only and one for the case in which government consumption can serve as a substitute for private consumption.

The critical parameter for the analysis is the weight between consumption and leisure, $\alpha$. The labor share $1-\theta$ is also important for the analysis but the results are less sensitive to it. The value of $\alpha$ is obtained by the calibration given the predictions of the model and the data for France, United States, and United Kingdom. The idea of using three different countries other than Portugal to obtain the value of $\alpha$, and keeping $\alpha$ constant, highlights the fact that only taxes change across countries and time while institutions do not change. Therefore, changes in labor supply are explained by changes in tax rates.

The value of $\alpha$, in turn, depends on the effective tax rates. Therefore, we have to be especially concerned with the calculations of the effective tax rates in the sensitivity analysis. The procedure to obtain the effective tax rates, dividing the tax revenue by the tax base, however, is done directly with the revenue and national account 
statistics. This method is not very sensitive to specific assumptions. There is not a direct assumption on $\alpha$. Using the parameters calculated independently in other studies and setting $\alpha$ by the evidence in the data provides discipline in the selection of the parameters for the exercise.

A parameter in the calculations of effective tax rates that does not come directly from data is the adjustment from average to marginal labor income taxes. As described above, the effective tax on labor is given by $\tau_{h}=\tau_{S S}+f \tau_{h}^{a v g}$, where $f$ is a factor used to adjust the average tax rate to a marginal tax rate. The average tax rate $\tau_{h}^{a v g}$ is calculated directly from revenue and National Accounts data. In the benchmark prediction, $f=1.6$, equal to the value set by Prescott $(2002,2004)$ and calculated as the increase in tax revenues if all workers had an increase in their incomes of one percent.

The labor share also affects predictions by its role in the calculation of the Social Security $\operatorname{tax} \tau_{S S}$. If the labor share increases, then the estimated labor income share increases and the tax base used to calculate $\tau_{S S}$ increases. Also, the labor share influences directly the value of hours given by the model in equation (3). The labor share in the predictions was set to 0.7 .

In the sensitivity analysis, I first recalculate the predictions for the sets of parameters given by $1-\theta=0.65$ and 0.70 , and for $f=1.4,1.6$ and 1.8 for the five countries. The benchmark combination is $1-\theta=0.70$ and $f=1.6$, used in section 4 . For each combination, I calculate the predictions with private consumption only and with government consumption as a substitute for private consumption. This gives a total of 50 additional simulations. Table 3 shows the results.

In general, the changes in $f$ and in the labor share yield parallel changes in the effective tax rates. This changes the value of $\alpha$ to adjust to the new effective tax rates. The value of $\alpha$ increases when the labor share increases and decreases when $f$ increases. As the new series is parallel to the series first calculated, the new predictions 
maintain the pattern first obtained.

\begin{tabular}{|c|c|c|c|c|c|c|c|c|c|c|c|c|c|}
\hline & \multirow{3}{*}{$\begin{array}{r}\text { Portugal } \\
\text { Actual } \\
\end{array}$} & \multicolumn{6}{|c|}{$1-\theta=0.7$} & \multicolumn{6}{|c|}{$1-\theta=0.65$} \\
\hline & & \multicolumn{2}{|c|}{$f=1.4$} & \multicolumn{2}{|c|}{$f=1.6$} & \multicolumn{2}{|c|}{$f=1.8$} & \multicolumn{2}{|c|}{$f=1.4$} & \multicolumn{2}{|c|}{$f=1.6$} & \multicolumn{2}{|c|}{$f=1.8$} \\
\hline & & Pred 1 & Pred 2 & Pred 1 & Pred 2 & Pred 1 & Pred 2 & Pred 1 & Pred 2 & Pred 1 & Pred 2 & Pred 1 & Pred 2 \\
\hline $1970-74$ & - & - & - & - & - & - & - & - & - & - & - & - & - \\
\hline 1983-86* & 35.1 & 35.9 & 37.3 & 36.2 & 37.7 & 36.5 & 38.0 & 35.9 & 37.4 & 36.2 & 37.7 & 36.6 & 38.0 \\
\hline 1993-96 & 33.9 & 33.5 & 33.4 & 33.6 & 33.5 & 33.7 & 33.6 & 33.5 & 33.4 & 33.6 & 33.5 & 33.7 & 33.5 \\
\hline $2000-02 * *$ & 32.6 & 33.5 & 32.3 & 33.5 & 32.4 & 33.6 & 32.4 & 33.3 & 32.1 & 33.4 & 32.2 & 33.5 & 32.2 \\
\hline \multicolumn{14}{|c|}{$\begin{array}{c}2000-02^{* *} \\
\text { Spain }\end{array}$} \\
\hline $1970-74$ & - & - & - & - & - & - & - & - & - & - & - & - & - \\
\hline 1983-86 & 36.0 & 35.1 & 36.6 & 35.3 & 36.8 & 35.5 & 37.0 & 35.0 & 36.5 & 35.2 & 36.7 & 35.4 & 36.8 \\
\hline $1993-96$ & 34.9 & 33.9 & 34.0 & 33.9 & 34.0 & 33.8 & 33.9 & 33.7 & 33.9 & 33.7 & 33.8 & 33.7 & 33.7 \\
\hline 2000-02 & 34.9 & 34.6 & 34.6 & 34.6 & 34.7 & 34.6 & 34.6 & 34.4 & 34.4 & 34.4 & 34.4 & 34.5 & 34.4 \\
\hline \multicolumn{14}{|c|}{ United States } \\
\hline $1970-74$ & 36.3 & 37.0 & 38.1 & 37.0 & 38.1 & 37.0 & 38.1 & 37.2 & 38.3 & 37.2 & 38.3 & 37.2 & 38.3 \\
\hline $1983-86$ & 35.1 & 35.3 & 36.6 & 35.2 & 36.5 & 35.1 & 36.4 & 35.3 & 36.7 & 35.3 & 36.6 & 35.2 & 36.5 \\
\hline 1993-96 & 35.2 & 33.9 & 36.0 & 33.8 & 35.9 & 33.7 & 35.7 & 34.0 & 36.0 & 33.9 & 35.9 & 33.8 & 35.8 \\
\hline 2000-02 & 34.8 & 32.4 & 34.7 & 32.1 & 34.5 & 31.8 & 34.1 & 32.4 & 34.8 & 32.1 & 34.5 & 31.9 & 34.2 \\
\hline \multicolumn{14}{|c|}{ United Kingdom } \\
\hline $1970-74$ & 36.6 & 35.1 & 35.0 & 34.8 & 34.8 & 34.5 & 34.4 & 35.2 & 35.1 & 34.9 & 34.8 & 34.6 & 34.5 \\
\hline $1983-86$ & 33.5 & 34.7 & 33.4 & 34.4 & 33.2 & 34.1 & 32.9 & 34.7 & 33.4 & 34.4 & 33.2 & 34.2 & 32.9 \\
\hline 1993-96 & 33.3 & 33.9 & 33.5 & 33.7 & 33.4 & 33.5 & 33.1 & 34.0 & 33.6 & 33.8 & 33.4 & 33.6 & 33.2 \\
\hline \multirow{2}{*}{\multicolumn{14}{|c|}{ France }} \\
\hline & & & & & & & & & & & & & \\
\hline $1970-74$ & 35.9 & 36.9 & 36.1 & 37.2 & 36.4 & 37.6 & 36.7 & 36.7 & 35.9 & 37.0 & 36.2 & 37.4 & 36.6 \\
\hline 1983-86 & 31.6 & 31.9 & 29.4 & 31.9 & 29.6 & 32.0 & 29.6 & 31.3 & 28.9 & 31.4 & 29.0 & 31.5 & 29.1 \\
\hline $1993-96$ & 30.2 & 32.5 & 29.8 & 32.6 & 29.9 & 32.7 & 30.0 & 31.9 & 29.2 & 32.0 & 29.3 & 32.1 & 29.4 \\
\hline 2000-02 & 28.3 & 32.6 & 29.9 & 32.4 & 29.8 & 32.2 & 29.6 & 32.1 & 29.5 & 31.9 & 29.3 & 31.7 & 29.1 \\
\hline
\end{tabular}

In the new calculations, most predictions still maintain the difference from actual values of one hour or less. The predictions slightly improve when $f$ decreases and slightly worsen when the labor share decreases. For example, from the benchmark $f=1.6$ and labor share of 0.7 , the proportion of predictions within one hour or less from the actual values increases from 61 percent to 67 percent when $f$ decreases to 1.4 - keeping the labor share fixed - and decreases to 58 percent when the labor share decreases to 0.65 - keeping $f$ fixed. On the other hand, the number of predictions that misses the actual values for more than two hours increases from five to seven when we maintain the labor share and increase $f$ to 1.8. These results suggest that the factor $f$ in fact makes the fit of the model more difficult. Hence, I also calculated the predictions for the benchmark labor share with no correction factor, $f=1$, and confirmed this suggestion. The number of predictions that misses the actual values for two hours or more decreases to four and the predictions are closer to the actual 
values as compared to the benchmark.

Therefore, results improve from the benchmark in table 2 for $1-\theta=0.7$ and $f=1.4$ and worsen for $1-\theta=0.7$ and $f=1.8$. The changes, however, are not substantial and the conclusions are not particular to the parameters chosen in the sections above. The conclusions do not change either when we consider only private consumption and the sum of private and government consumption.

Going further from the assumptions made on the parameters, the method used to calculate effective tax rates may also affect results. As described in section 3 , I followed the method as set by Mendoza, Razin and Tesar (1994) and Prescott (2002, 2004). The principle of the calculations is to use tax revenues and the tax base to obtain effective tax rates, but there are small differences in the calculations. I discuss below if these differences can affect conclusions.

For the consumption tax, $\tau_{c}$, as stated in section 3, Mendoza, Razin and Tesar take into account the fact that part of the indirect taxation comes from taxes paid by the government. Hence, they include the difference between government consumption and wages of government employees in the tax base. For Portugal, this would imply a series from 1995 instead of 1970 as we have in table 1. Moreover, this could add a measurement error as countries may differ in the way government employees are considered. Finally, both the level and the variation of this additional term in the tax base are small relative to the level and variation of consumption and indirect taxation. Therefore, the implied series is close and moves in parallel to the series used in the calculations. As a result, including government consumption and wages of government employees would not change the conclusions of the paper.

For the labor income tax, Prescott first calculates the Social Security tax using data on Social Security contributions and an estimate of labor income with the labor share parameter. He then adds the average income tax, calculated by direct taxes and GDP minus indirect taxes and depreciation, adjusted to account for marginal tax. 
Mendoza, Razin and Tesar, on the other hand, first calculate the average tax on total income with the figures on operating surplus of private unincorporated enterprises (OSPUE) and household's property and entrepreneurial income (PEI), use this value and wages to estimate tax revenues from labor income and, finally, add Social Security contributions. This method relies more heavily on the revenues data but has two disadvantages for the analysis in this paper. The first is that the series for OSPUE, PEI and wages are not as easily available as the other series. For Portugal and Spain, for example, the available series for these items start in 1995. The second is that OSPUE and PEI are difficult to measure and are more sensible to different rules according to the country. This is discussed in detail by Gollin (2002), especially for OSPUE. Nevertheless, I calculated the effective labor tax rates also using this method. Again, the two series move in parallel for each country and they have similar values $^{15}$. Therefore, using this alternative method would limit the analysis because of the availability of data, but would not change the conclusions of the paper.

Therefore, we studied first how the assumptions on the labor share and on the adjustment factor $f$ could affect results and, second, how different methods on the calculation of the effective tax rates could affect results. The difference between the predictions do not change in fundamental ways for all modifications proposed. We are able to conclude that the results of the paper are not sensitive to special assumptions made in the present analysis.

\section{POLICY IMPLICATIONS}

According to the analysis above, taxes influence labor supply and we have a model able to explain labor supply movements. Why do these results matter? This section examines further the results by calling attention to their policy implications. I

\footnotetext{
${ }^{15}$ For Portugal and Spain, the two series used for the predictions are below the series calculated by this method by around one percentage point.
} 
especially examine the policy implications for Portugal.

As aggregate labor supply reacts negatively to an increase in taxes, governments should take this into account when devising the tax structure. This statement is surprising because the first estimates of the labor supply elasticity pointed to a small number. The difference is that these estimates were obtained with micro-level data while this paper considers aggregate data ${ }^{16}$.

As agents react to taxes, an increase in tax rates creates distortions that decrease output, capital and consumption. In order to calculate the long-run implications of a change in the tax structure, consider the economy in a balanced growth path: consumption, output and capital grow at the same rate $\gamma$, equal to the productivity growth rate, and hours of work are constant. Define the welfare compensation $v$ as the percentage increment in lifetime consumption that would make consumers under the current policy indifferent to the proposed policy. Use $\alpha=1.02$, calibrated in section 4 , and $\theta=0.3$, used in sections 3 and 4 . It is interesting to consider a change in the tax structure maintaining the ratio of government expenditures to GDP constant. Set, therefore, $G / Y=0.19$, the average for Portugal from 1989 to 2001 according to OECD data. Set the productivity growth rate equal to 2 percent per year, and the values of $\beta$ and $\delta$ such that the net interest is equal to 4 percent and the capital-output ratio is compatible with the value for Portugal ${ }^{17}$.

Consider first a decrease in taxes in Portugal from 45 percent to the level of taxes in the United States of 37 percent. These tax rates refer to the average of $\tau$, which includes consumption and labor taxes, in the period 1999-2001. This decrease in taxes is equivalent to an increase in 6.8 percent in lifetime consumption. This welfare gain

\footnotetext{
${ }^{16} \mathrm{~A}$ recent discussion about the reasons for the difference in estimation with aggregate and micro data is in Rogerson (2006). Rogerson and Wallenius (2007) provide an economic model to explain the different estimations.

${ }^{17}$ This yields $\beta=0.9811$ and $\delta=0.046$, for the tax rates for Portugal, and implies $k / y=3.5$, in accordance to the data by Klenow and Rodrigues-Clare (1997). For the Social Security exercise below, $\beta=0.9844$. These and the other parameters have a small effect on the welfare compensations.
} 
takes into account the increase in hours of work from 31 to 34 hours. Note that this decrease in taxes keeps constant the ratio of government expenditures on total GDP. Capital and output increase 10.7 percent. As $G / Y$ is fixed, government expenditures also increase 10.7 percent $^{18}$. Therefore, as $\tau$ decreases, agents consume more, work more, and accumulate more capital.

Now consider the two increases in the value added tax rate in Portugal in 2002 and 2005. The consumption tax rate increased 2 percentage points in each increase. The model implies a total welfare loss of 1.5 percent from the total increase of 4 percentage points. This roughly reflects the welfare loss of 0.8 percent from each increase. The model also implies a total decrease in capital and output of 2.1 percent.

The welfare effects of changes in taxes are substantial. They are higher than various estimates of the welfare loss of, for example, an increase in inflation from zero to 10 percent per year and of business cycles. These estimates may be conservative, however, as they do not consider a decrease in the productivity level or growth rate caused by the smaller quantity of capital.

\section{Social Security}

The findings can also be used to discuss possible alternatives to reform Social Security. Social Security systems are usually financed with the contributions of current young to current old generations. For Portugal, this system implied a ratio of 22 contributors to pensioners in 1960 but only 1.7 contributors to pensioners in 2000. Total Social Securities expenditures as a fraction of GDP increased from 1.4 to 9.3 percent in the same period ${ }^{19}$. The decrease in the number of contributors to pensioners and the increase in Social Security expenditures threatens the solvency of the system.

One solution is to change the current system, known as pay-as-you-go (PAYG), to

\footnotetext{
${ }^{18}$ The welfare compensation takes into account the increase in $G$. If this is not taken into account, then the welfare gain decreases to 5.3 percent. If only private consumption is considered with $\alpha=1.39$, then $v=5.8$ percent.

${ }^{19}$ Socal Security data from Rodrigues (2006), table 2.1, p. 52.
} 
a fully funded system. Benefits in a fully funded system work in the same way as private savings, that is, benefits are the result of individual contributions to individual accounts. The government may specify a minimum contribution per period. The problem is that the transition from PAYG to fully funded may leave the current old generation without their benefits. The finding that labor supply is sensitive to taxes, however, implies that a decrease in Social Security taxes increases labor supply and output. This helps to finance the transition.

In order to study Social Security we have to move from the representative consumer in the previous sections to an economy with workers and retired agents. Therefore, consider an overlapping generations economy, as in Auerbach and Kotlikoff (1987), with 60 generations $^{20}$. Suppose that agents live 41 years as active workers and 19 years as retired workers. If agents start to work at 22 , this implies that they retire at $63^{21}$. Suppose that the interest rate is constant and equal to 4 percent and that wages increase at the rate of 2 percent per year. These values are the same for the economy above with infinitely-lived agents, the difference is that now they are assumed instead of being calculated in equilibrium. We can understand this assumption by supposing a technology with perfect substitution between capital and labor, as Prescott (2004), or by considering the economy as a small open economy, as Huang et al. (1997).

Labor income is taxed at the rate $\tau$, equal to the sum of the Social Security contribution and the tax on labor income. In a PAYG Social Security system, Social

\footnotetext{
${ }^{20}$ The following simulations study some options for Portugal and instigate further analyses. It is beyond the scope of the paper to offer a detailed analysis of a reform of the Social Security system. For more complex models of Social Security see, for example, Kotlikoff et al. (1999) and Imrohoroglu et al. (1999), for models with overlapping generations closer in spirit to the present analysis; and volume 2 of the Review of Economic Dynamics, dedicated entirely to Social Security. Prescott (2004) discusses a Social Security reform for the United States. I make different assumptions on the parameters and on the details of the Social Security system. I also consider different options for the transition.

${ }^{21}$ I use the same number of periods for active and retired workers as Prescott to facilitate comparison. These numbers are similar to the numbers for Portugal. According to the Anuário Estatístico do INE 2005, p. 123, the average retirement age for Portugal is 62 years.
} 
Security contributions are used to finance the benefits to the current retired. The sum of benefits paid across generations of retired workers is equal to the sum of the contributions paid by the generations of active workers. The labor income tax is used to finance government expenditures not related to Social Security. As in section 2, any difference between tax collection and expenditures is returned to all generations as lump-sum transfers ${ }^{22}$.

The individual maximization problem is similar to the problem of infinitely-lived agents. The difference is that now agents take into account the benefits that will be received when they are retired. Active agents decide how much to work and retired agents do not work. It suffices to show the problem of the first generation at time one, as the problems of the other generations are analogous. We have

$$
\max \sum_{t=1}^{60} \beta^{t-1}\left[\log c_{t}+\alpha \log \left(100-h_{t}\right)\right]
$$

subject to $c_{t}+A_{t}=(1-\tau) w_{t} h_{t}+(1+r) A_{t-1}+T_{t}$ when active, and $c_{t}+A_{t}=$ $(1+r) A_{t-1}+T_{t}+B$ when retired. $A_{t}$ stands for savings and $B$ are the Social Security benefits. In each period, there are 60 generations with similar problems. We obtain aggregate equilibrium values such as consumption, hours and capital by aggregating optimal choices across generations. In particular, capital is given by the sum of individual savings. In equilibrium, each generation receives a level of benefits during retirement, and the level of benefits increases at the rate $\gamma$ for each generation ${ }^{23}$.

What are the consequences of this Social Security system? Consider first a comparison of three economies in the steady state with different policies for the Social

\footnotetext{
${ }^{22}$ Auerbach and Kotlikoff (1987) do not have this kind of transfers, but they allow $\tau$ to change to satisfy the government budget constraint. Introducing transfers allows us to maintain taxes fixed and study different implications.

${ }^{23}$ These modifications of the original problem imply reasonable equilibrium values and individual dynamics. For a more complex model for the lifetime behavior of consumption and savings see, for example, Rios-Rull (1996). The model of Rios-Rull, on the other hand, does not have social security nor taxes, and completely abstracts from government.
} 
Security. The first simulates the current structure for Portugal, with a PAYG system and taxes as calculated in section 3. This implies $\tau=0.454$ and $\tau_{S S}=0.17$. Social security expenditures on pensions, however, include survivors and disability pensions. As old-age pensions constitute 70 percent of all expenditures on pensions, I set $\tau_{S S}=0.12$ to concentrate on pensions related to retirement. The second economy has a decrease of 1 percentage point of the Social Security tax. The third economy has a fully funded Social Security system. In this case, the government removes the Social Security tax and obliges agents to contribute an equivalent amount to a private account, which receives the 4 percent interest rate that prevails in the economy. When agents retire, they use savings from this account ${ }^{24}$. I keep the governmentoutput ratio fixed at 19 percent for the three economies ${ }^{25}$. Results are in table 4. The Social Security contribution in the first economy implies a replacement ratio of 37 percent $^{26}$.

\begin{tabular}{|c|c|c|c|c|c|c|c|}
\hline & Consumption $^{1}$ & Hours of Work ${ }^{1}$ & Output & Capital/Output & $\tau$ & $\tau_{\mathrm{SS}}$ & Welfare Gain $^{2}$ \\
\hline Policy 1 & 100.0 & 100.0 & 100.0 & 3.5 & 0.454 & 0.12 & - \\
\hline Policy 2 & 101.2 & 100.7 & 101.2 & 3.7 & 0.444 & 0.11 & $0.8 \%$ \\
\hline Policy 3 & 113.7 & 107.3 & 113.7 & 6.2 & 0.334 & 0.00 & $9.5 \%$ \\
\hline
\end{tabular}

As we can see from table 4 , moving from a PAYG to a fully funded system increases consumption, hours of work, output and the capital-output ratio. The increase in the capital-output ratio is large and it is compatible with the findings in Kotlikoff et al.

\footnotetext{
${ }^{24}$ As Kotlikoff et al. (1999) state, having this mandated private account for retirement is equivalent to setting the Social Security tax to zero since agents are not liquidity constraint in this economy.

${ }^{25}$ This is different from Kotlikoff et alii (1999), which keep $G$ fixed. I have also calculated the welfare effects with $G$ fixed (such that $G / Y=0.19$ for the first policy) and the difference is small. I have also calculated for $G=0$ and the welfare effects are also similar.

${ }^{26}$ The reference wage in Portugal is the average of the best 10 of the last 15 years of wages reported (Rodrigues, 2006, p. 64). It was calculated in the same way in the present paper. The replacement ratio in Portugal ranges between 30 to 80 percent for about 53 percent of the beneficiaries.
} 
(1999) and Prescott (2004). The welfare gains are substantial. Moving from a PAYG system to a fully funded is equivalent to a permanent increase of 9.5 percent of current consumption. A decrease of 1 percentage point in the Social Security contribution rate implies a welfare gain of 0.8 percent. Moving from PAYG to fully funded increases consumption 13.7 percent and increases hours of work 7.3 percent. The welfare gains take into account the increase in hours of work and the three policies have the same government-output ratio. That is, the level of government expenditures is higher when output is higher. The welfare gains decrease to 7.5 and 0.7 percent respectively when we do not consider the increase in government expenditures. The simulations for the first policy imply a ratio of pensions to GDP equal to 11 percent $^{27}$, this number decreases to 10 percent with a decrease of one percentage point in $\tau_{S S}$.

\section{Transition}

What are the effects of the transition from a PAYG system to a fully funded system? Suppose that the government offers the option of moving to a fully funded system. Social security benefits and contributions are eliminated for those that opt for the new system. Agents decide on the new system if the present value of Social Security contributions is higher than the present value of benefits.

From the perspective of the government, the difficulty of implementing this plan is on financing the benefits of the generations that decide to stay in the old system. As labor supply reacts to a decrease in taxes, however, it is possible to change to a fully funded Social Security system and maintain the benefits of the current old generations. Two forces help in this direction. The first is the increase in tax revenues used to finance government consumption. Total tax revenues equal $\left(\tau_{h}+\tau_{S S}\right) H_{t}$, where $H_{t}$ is aggregate labor income, but government consumption is financed with $\tau_{h} H_{t}$. When

\footnotetext{
${ }^{27}$ Even with the simplifications in this paper, it is interesting that the model is able to generate reasonable numbers for this ratio. Old-age pensions as a fraction of GDP are equal to 4.95 percent for Portugal in 2003 and the analogous figure for total Social Security expenditures is 12.5 percent (Rodrigues 2006, p. 63).
} 
$\tau_{S S}=0$, hours of work and labor income increase. Therefore, revenues used to finance government consumption increase. These additional revenues can be used to finance the Social Security deficit ${ }^{28}$. The second force is the gain of new generations born after the announcement of the change. As the gain of moving to a fully funded system is substantial, these generations can receive smaller non-Social Security transfers and even so be better off than with the PAYG system.

I consider two alternatives to finance the gap between benefits and contributions during the transition. In the first, I maintain government expenditures of the steady state with PAYG, growing at the constant 2 percent rate, and decrease transfers of the generations born in the period of the change and afterwards. The level of transfers for the remaining generations are maintained, including for the ones that opt to move to the fully funded system. The level of benefits are maintained for those that stay in the old system. Any difference between government revenues and expenses are financed by bonds. Bonds receive the same interest rate of 4 percent that agents receive in their private accounts. The decrease in transfers produces a surplus before interest payments such that the debt to output ratio is constant in the long run.

The second alternative sets the level of transfers for generations born on and after the change equal to its new steady state level, such that the long-run ratio of government to output is maintained at 19 percent, and temporarily decreases government expenditures in order to finance any difference between benefits and contributions. This alternative implies higher output, consumption and government expenditures in the long run. If agents value government expenditures, however, some generations can be worse off by the temporary decrease in government expenditures relative to its values with no transition.

Figure (6) shows the transitional dynamics for the two alternatives. The first 25 generations opt for the new system in the announcement of the change. As the open-

\footnotetext{
${ }^{28}$ Total tax revenues $\left(\tau_{h}+\tau_{S S}\right) H_{t}$ decrease.
} 

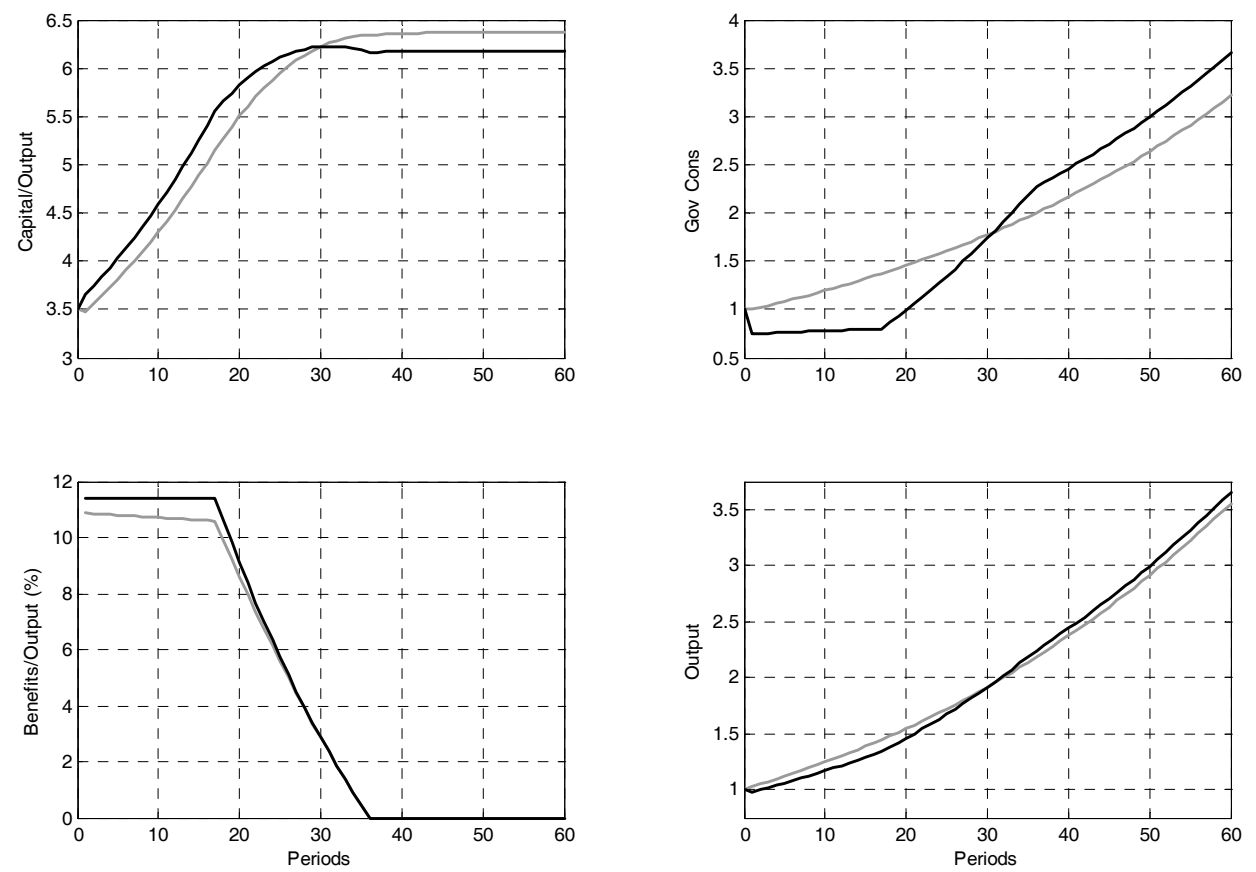

FIG. 6. Transition from a PAYG to a Fully-Funded Social Security system. Black line: Social Security deficit financed with a temporary decrease in government expenditures. Gray line: Social Security deficit financed with a decrease in lump-sum transfers for generations born in the period and after the change.

economy assumption sets wages and interest rates exogenously, these generations behave as if they were in the new steady state. The transition takes 35 years, the number of years for the generation that continue in the old system to exit. The ratio of benefits to output is initially constant in both alternatives as newly retired agents in the old system start to receive their benefits and older generations leave the economy. Eventually, the ratio of benefits to output decrease to zero as no additional generation starts to receive benefits.

In the first alternative, government consumption continues to grow from its initial steady state level at the 2 percent growth rate. As output under $\tau_{S S}=0$ is higher, 
however, the government-output ratio decreases to 17 percent in the long run. The welfare gain for the first generation is 4.8 percent in terms of current consumption if we consider government consumption. The welfare gain rises to 6.2 percent if we only consider private consumption ${ }^{29}$. Older generations are indifferent to this change as the government consumption path and their consumption and hours do not change. This alternative implies a high long-run debt to output ratio, equal to 1.8.

In the second alternative, the economy converges to the steady state described in table 4 , with $\tau_{S S}=0$ and government-consumption ratio equal to 19 percent. Government consumption has to be temporarily below its trend in order to cover the Social Security deficit. When the number of Social Security beneficiaries decreases, government consumption increases towards its trend. Government consumption is eventually higher than in the first alternative. The welfare gain for the first generation is 3.0 and 7.5 percent respectively if we consider or not government consumption. As government consumption is temporarily smaller, older generations are worse off under this alternative if they value government consumption.

It is beyond the purpose of this paper to offer an exhaustive Social Security model with all possibilities for the transition ${ }^{30}$. Nevertheless, the present discussion on the Social Security offers a first analysis of the effects in the Portuguese economy of a change from a PAYG system to a fully funded system with the model developed in section 2. As we can see, the effects and the welfare gains are substantial.

\section{CONCLUSIONS}

Tax rates affect the decision of labor supply. The effect is large. For Portugal, France, Spain, United Kingdom and United States, taxes are able to predict the

\footnotetext{
${ }^{29}$ The welfare gains are smaller than the ones shown in table 4 because transfers are smaller in this alternative and because long run government consumption is higher if we keep $G / Y=0.19$.

${ }^{30}$ For example, Imrohoroglu et al. (1999) consider an economy with land, Kotlikoff et al. (1999) consider intragenerational heterogeneity and different options to finance the transition.
} 
pattern of the labor supply over the years. These conclusions are not sensitive to specific assumptions.

These results are important for at least three reasons. First, it shows that taxes influence labor supply in a relevant way. Second, it implies that an increase in taxes decreases welfare substantially by the distortionary effect on labor supply. Finally, the effect on labor supply provides a way to finance Social Security by letting workers choose between continuing in the system or saving privately.

Other features may affect hours worked and the labor market. Bover, GarciaPerea and Portugal (2000) and Blanchard and Portugal (2001) analyze the role of unemployment benefits and other factors. Alesina, Glaeser and Sacerdote (2005) focus on unions and labor market regulations.

If we are more efficient trading goods in the market, a decrease in market hours makes consumers less efficient. To foster economic growth, we have to look for ways to reach economic efficiency. Paying attention to the labor decisions is one of them.

\section{REFERENCES}

Alesina, Alberto, Edward Glaeser and Bruno Sacerdote (2005). "Work and Leisure in the U.S. and Europe: Why So Different?" NBER Macroeconomic Annual 2005: 1-64. Cambridge, MA: MIT Press.

Auerbach, Alan J. and Laurence J. Kotlikoff (1987). Dynamic Fiscal Policy. Cambridge, England: Cambridge University Press.

Blanchard, Olivier and Pedro Portugal (2001). "What Hides Behind an Unemployment Rate: Comparing Portuguese and U.S. Labor Markets." American Economic Review, 91(1): 187-207.

Bover, Olympia, Pilar Garcia-Perea and Pedro Portugal (2000). "Labour 
Market Outliers: Lessons from Portugal and Spain." Economic Policy, 15(31): $379-428$.

Cooley, Thomas F. (ed.) (1995). Frontiers of Business Cycle Research. Princeton: Princeton University Press.

Davis, Steven J., and Magnus Henrekson (2005). "Tax Effects on Work Activity, Industry Mix and Shadow Economy Size: Evidence from Rich-Country Comparisons." In Gomez-Salvador, R., A. Lamo, B. Petrongolo, M. Ward, and E. Wasmer (eds.), Labour Supply and Incentives to Work in Europe. Cheltenham and Northampton: Edward Elgar.

Gollin, Douglas (2002). "Getting Income Shares Right." Journal of Political Economy, 110(21): 458-474.

Huang, He, Selahattin Imrohoroglu, and Thomas J. Sargent (1997). "Two Computations to Fund Social Security." Macroeconomic Dynamics, 1(1): 7-44.

Imrohoroglu, Ayse, Selahattin Imrohoroglu, and Douglas H. Joines (1999). "Social Security in an Overlapping Generations with Land." Review of Economic Dynamics, 2(3): 638-665.

Klenow, Peter J. and Andrés Rodriguez-Clare (1997). "The Neoclassical Revival in Growth Economics: Has It Gone Too Far?" NBER Macroeconomics Annual 1997: 73-103. Cambridge, MA: MIT Press.

Kotlikoff, Laurence J., Kent Smetters and Jan Walliser (1999). "Privatizing Social Security in the United States: Comparing the Options." Review of Economic Dynamics, 2(3): 532-574.

Lucas, Robert E., Jr. (1990). "Supply-Side Economics: an Analytical Review." Oxford Economic Papers, 42(2): 293-316. 
Mendoza, Enrique G., Assaf Razin, and Linda L. Tesar (1994). "Effective Tax Rates in Macroeconomics: Cross-Country Estimates of Tax Rates on Factor Incomes and Consumption." Journal of Monetary Economics, 34(3): 297-323.

Pereira, Alfredo Marvão and Pedro Rodrigues (2001a). "Tax Parameters in the Portuguese Economy: Part I - Indirect Taxes." Banco de Portugal Economic Bulletin, March.

Pereira, Alfredo Marvão and Pedro Rodrigues (2001b). "Tax Parameters in the Portuguese Economy: Part II - Direct Taxes." Banco de Portugal Economic Bulletin, June.

Prescott, Edward C. (2002). "Prosperity and Depression." American Economic Review, 92(2): 1-15.

Prescott, Edward C. (2004). "Why Do Americans Work So Much More Than Europeans?" Federal Reserve Bank of Minneapolis Quarterly Review, 28(1): 2-13.

Rios-Rull, Jose-Victor (1996). "Life-Cycle Economies and Aggregate Fluctuations." Review of Economic Studies, 63(3): 465-489.

Rodrigues, Pedro G. (2006). Pension Reform in Portugal: a Dynamic General Equilibrium Analysis. Ph.D. Dissertation, Department of Economics, Universidade Nova de Lisboa.

Rogerson, Richard (2006). "Understanding Differences in Hours Worked." Review of Economic Dynamics, 9(3): 365-409.

Rogerson, Richard and Johanna Wallenius (2007). "Micro and Macro Elasticities in a Life Cycle Model With Taxes." NBER Working Paper 13017. 